\title{
Effects of atrial pacing site on atrial and atrioventricular nodal function ${ }^{1}$
}

\author{
Fernando Amat y Leon, Pablo Denes, Delon Wu, Raymond J. Pietras, and Kenneth M. Rosen \\ From the Section of Cardiology, Department of Medicine, Abraham Lincoln School of Medicine, University of \\ Illinois College of Medicine, Chicago, Illinois, U.S.A.
}

The effects of the site used for atrial pacing on atrial and atrioventricular nodal conduction were assessed in I6 patients. In 13 patients, three atrial pacing sites were used: high right atrium, low lateral right atrium, and midcoronary sinus. Two recording sites were used: low septal right atrium, including His electrogram, and high right atrium. Stimulus $(S)$ to high right atrium interval was longest with coronary sinus pacing $(76 \pm 7 \mathrm{~ms})(P<0.001)$, and shortest with high right atrial pacing $(4 I \pm 3 \mathrm{~ms})(P<0.05)$. There was no significant difference in stimulus to low septal right atrium from all three pacing sites. Atrial functional and effective refractory periods were not significantly different. Mean low septal right atrium to His was significantly shorter from the coronary sinus $(93 \pm 8 \mathrm{~ms})(P<0.001)$, as compared to high right atrium (I39 \pm 16 $\mathrm{ms}$ ), and low lateral right atrium (I29 $\pm 13 \mathrm{~ms}$ ) pacing. $A V$ nodal functional and effective refractory periods, and the paced rate producing $A V$ nodal Wenckebach were not significantly different when comparing the three sites.

Left atrial appendage and high right atrium were similarly compared in three additional patients, and no significant differences were found in conduction times and refractory periods.

Electrophysiological studies in the catheterization laboratory are used to study conduction physiology, pathophysiology, and pharmacology. In these studies, conduction intervals and their responses to atrial pacing are measured. Refractory periods are determined using the atrial extra-stimulus technique. Previous studies suggest that atrial stimulation site might influence electrophysiological findings (Waldo et al., 1970; Leon et al., 1970; Lau et al., 1970; Lancaster et al., I965; Janse, 1969). In this study, we have systematically studied the effects of atrial pacing site on atrial and AV nodal conduction times and refractory periods.

\section{Methods}

This study was conducted in 16 patients: 12 had electrophysiological evaluation because of intraventricular conduction disease, and 4 had electrophysiological studies performed after diagnostic cardiac catheteriza-

Received 7 October 1974.

${ }^{1}$ Supported in part by NIH Contract under the Myocardial Infarction Program, National Heart and Lung Institute, National Institutes of Health, Department of Health, Education and Welfare. tion. Informed consent was obtained. Clinical data in the I6 patients are summarized in Table $I$.

All patients were studied in the post-absorptive, nonsedated state. A tripolar electrode catheter was introduced percutaneously into the right femoral vein and placed across the tricuspid valve for $\mathrm{His}$ bundle recording (Scherlag et al., I969). A quadripolar electrode catheter was introduced into the left femoral vein and advanced into the high lateral right atrium for both recording of atrial electrograms and for atrial stimulation. A bipolar electrode catheter, introduced via the antecubital vein, was used for pacing the low lateral right atrium and coronary sinus. The interelectrode distances in the bi, tri, and quadripolar catheters were I cm. Refractory periods were determined using the atrial extra-stimulus technique (Denes et al., 1974). Previous definitions of atrial and AV nodal effective and functional refractory periods were used (Denes et al., 1974). Stimuli were $2 \mathrm{~ms}$ in duration and twice diastolic threshold in intensity, delivered by a digital programmable pulse generator. ${ }^{1}$ Intracardiac electrograms, as well as electrocardiographic standard leads I, II, III, and chest lead VI were simultaneously displayed on an oscilloscope and recorded on a multichannel photographic recorder (Electronics for Medicine DR-16, White Plains, New York) at paper speeds of 100 and $200 \mathrm{~mm} / \mathrm{s}$.

${ }^{1}$ M. Bloom, Philadelphia, Pa., U.S.A. 
TABLE I Clinical, electrocardiographic, and electrophysiological data in 16 patients

\begin{tabular}{|c|c|c|c|c|c|c|c|c|}
\hline $\begin{array}{l}\text { Case } \\
\text { No. }\end{array}$ & $\operatorname{Age}(y r)$ & Sex & Diagnosis & $E C G$ & $\begin{array}{l}H R \\
\text { (beats/min) }\end{array}$ & $\begin{array}{l}P-A \\
(m s)\end{array}$ & $\begin{array}{l}A-H \\
(m s)\end{array}$ & $\begin{array}{l}H-V \\
(m s)\end{array}$ \\
\hline I & 56 & $\mathbf{F}$ & ASHD & CRBBB + LAH & 70 & 26 & 125 & 72 \\
\hline 2 & 42 & $\mathbf{F}$ & PCD & IRBBB + LPH & 68 & 26 & 93 & 43 \\
\hline 3 & 71 & $\mathbf{M}$ & PCD & CRBBB + LAH & 56 & 40 & IIO & 43 \\
\hline 4 & 72 & $\mathbf{M}$ & HCVD & CRBBB + LAH & 71 & 34 & IOI & 63 \\
\hline 5 & 26 & $\mathrm{~F}$ & RHD & $\mathrm{LVH}+\mathrm{I}^{\circ} \mathrm{A}-\mathrm{V}$ & 76 & 26 & 145 & 52 \\
\hline 6 & 62 & $\mathbf{M}$ & ASHD & $\mathrm{LBBB}+\mathrm{I}^{\circ} \mathrm{A}-\mathrm{V}$ & 66 & 21 & 168 & 83 \\
\hline 7 & 70 & $\mathbf{F}$ & HCVD & CRBBB & 73 & 45 & 107 & 49 \\
\hline 8 & 65 & $\mathbf{M}$ & HCVD & CRBBB + LAH & 83 & 49 & 76 & 65 \\
\hline 9 & 38 & $M$ & PCD & IRBBB + LAH & 55 & 32 & 154 & 44 \\
\hline I0 & 64 & $\mathbf{M}$ & HCVD & CRBBB + LAH & 46 & 40 & 107 & 43 \\
\hline II & 66 & $\mathbf{M}$ & PCD & $\mathrm{CRBBB}+\mathrm{LAH}$ & 67 & 46 & 104 & 32 \\
\hline 12 & 26 & $\mathbf{M}$ & RHD & Normal & 82 & 28 & 105 & 46 \\
\hline 13 & 45 & $\mathbf{F}$ & RHD & Normal & 75 & 32 & 105 & 42 \\
\hline 14 & 47 & $\mathrm{M}$ & PCD & IRBBB & 44 & 40 & 84 & 50 \\
\hline 15 & 68 & $\mathbf{M}$ & ASHD & CRBBB + LAH & 82 & 45 & 82 & 77 \\
\hline 16 & 32 & $\mathbf{F}$ & NoHD & QT Prolongation & 65 & 25 & 83 & 38 \\
\hline
\end{tabular}

Abbreviations: M, male; F, female; ASHD, arteriosclerotic heart disease; PCD, primary conduction disease; HCVD, hypertensive cardiovascular disease; RHD, rheumatic heart disease; NoHD, no organic heart disease; LBBB, left bundle-branch block; CRBBB, complete right bundle-branch block; IRBBB, incomplete right bundle-branch block; LAH, left anterior hemiblock; LPH, left posterior hemiblock; LVH, left ventricular hypertrophy; HR, heart rate; $I^{\circ} A-V$, Ist degree atrioventricular block.

Location of pacing and recording sites used The locations of pacing and recording electrode catheters are shown in Fig. I. Three stimulation sites were studied in 13 of the patients, these being: 1 ) high lateral right atrium at the junction of the superior vena cava and right atrium; 2) low lateral right atrium just above the junction of the inferior vena cava and low right atrium, and 3) the midportion of the coronary sinus (a posterior left atrial pacing site). The position of the catheter in the coronary sinus was confirmed by its posterior location in the lateral view and by the presence of inverted $P$ waves in leads II and III during stimulation. In addition, in a separate group of three patients, the left atrial appendage was paced and compared to the high right atrium. In these three patients, the left atrium could be entered via a patent foramen ovale.

The following two atrial recording sites were used (Fig. I): I) high right atrium, recorded from the quadri-
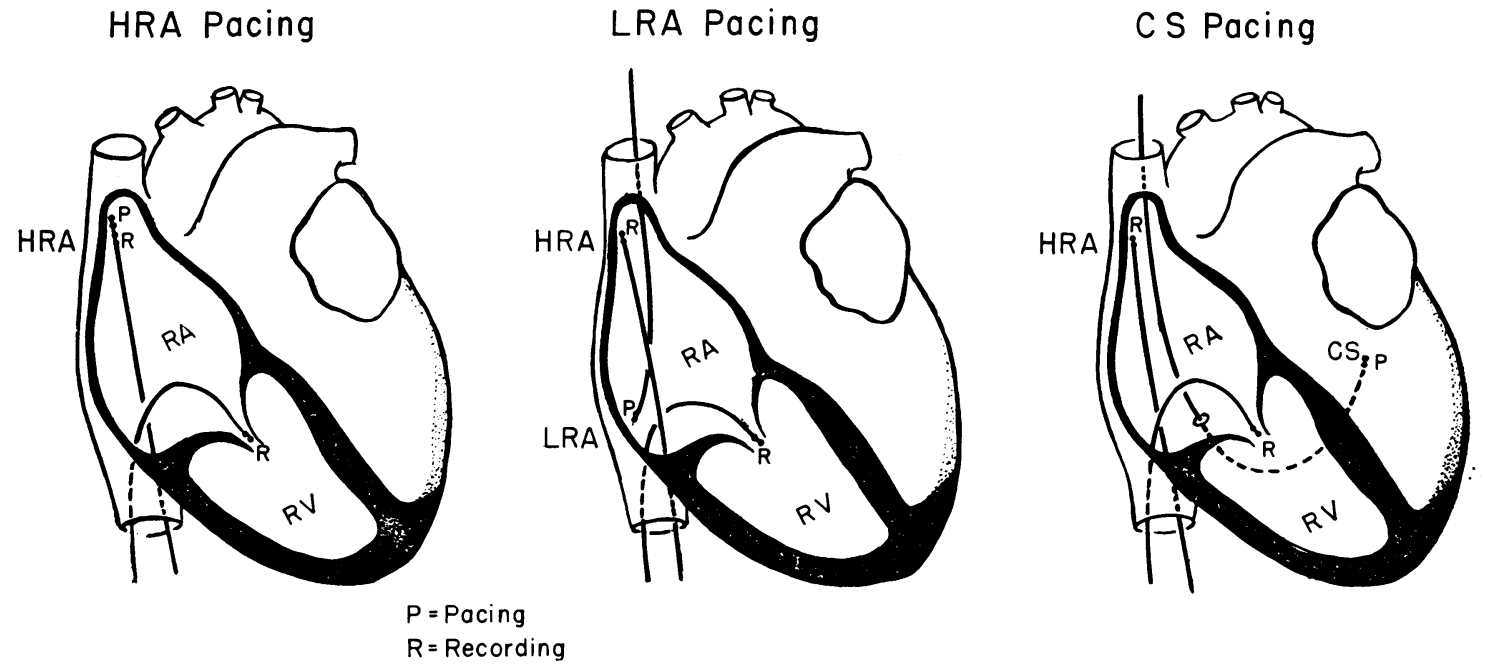

FIG. I Location of pacing and recording sites utilized. $H R A=$ high right atrium; $L R A=$ low lateral right atrium; $C S=$ midportion of the coronary sinus; $P=$ pacing site; $R=$ recording sites; $R A=$ right atrium; $R V=$ right ventricle. 
polar catheter; and 2) low septal right atrium, recorded from the His bundle catheter.

\section{Protocol}

The following protocol was used. In 13 patients, the three pacing sites were studied sequentially, beginning with the high right atrium, then with the low lateral right atrium, and concluding with the coronary sinus. In three patients, the left atrium was studied and compared to the high right atrium. At each site, the atria were paced at increasing rates until AV nodal Wenckebach periods were observed. The following intervals were then measured and compared at a cycle length of $667 \mathrm{~ms}$ : I) $\mathrm{S}-\mathrm{H}$, from stimulus to His bundle electrogram. This measured total conduction time from stimulus (at a given pacing site) to His bundle: 2) A-H from low septal right

TABLE 2 Conduction times and refractory periods in I6 patients

\begin{tabular}{|c|c|c|c|c|c|c|c|c|c|c|}
\hline \multirow[b]{2}{*}{$\begin{array}{l}\text { Case } \\
\text { No. }\end{array}$} & \multicolumn{5}{|c|}{ Atrial conduction times and refractory periods } & \multicolumn{5}{|c|}{$A V$ nodal conduction times and refractory periods } \\
\hline & $\begin{array}{l}\text { Pacing } \\
\text { site }\end{array}$ & $\begin{array}{l}S-H R A \\
(m s)\end{array}$ & $\begin{array}{l}S-A \\
(m s)\end{array}$ & $\begin{array}{l}F R P \text {-atr } \\
(m s)\end{array}$ & $\begin{array}{l}E R P \text {-atr } \\
(m s)\end{array}$ & $\begin{array}{l}S-H \\
(m s)\end{array}$ & $\begin{array}{l}A-H \\
(m s)\end{array}$ & $\begin{array}{l}W \\
\begin{array}{r}\text { (beats } \mid \\
\text { min) }\end{array}\end{array}$ & $\begin{array}{l}F R P-A V \\
(m s)\end{array}$ & $\begin{array}{l}E R P-A V \\
(m s)\end{array}$ \\
\hline \multirow[t]{3}{*}{ I } & HRA & 33 & 4I & 250 & 230 & 149 & Iro & 130 & 490 & 370 \\
\hline & LRA & 54 & 37 & 280 & 250 & 196 & 160 & 120 & 540 & 380 \\
\hline & CS & 60 & 40 & 300 & 280 & 145 & 103 & 130 & 500 & 404 \\
\hline \multirow[t]{3}{*}{2} & HRA & 32 & 58 & 270 & 260 & 158 & 100 & 120 & 590 & 450 \\
\hline & LRA & 90 & 85 & 240 & 230 & 255 & 170 & 120 & 580 & 490 \\
\hline & CS & 65 & 45 & 310 & 250 & 135 & 90 & IIO & 610 & 540 \\
\hline \multirow[t]{3}{*}{3} & HRA & 50 & 80 & $<350$ & $<350$ & 215 & 135 & 170 & 420 & $<350$ \\
\hline & LRA & 52 & 90 & - & - & 228 & 138 & 160 & - & - \\
\hline & CS & 60 & 50 & 310 & 260 & 168 & 118 & 160 & 410 & $<310$ \\
\hline \multirow[t]{3}{*}{4} & HRA & 36 & 79 & 280 & 260 & 185 & 107 & 170 & 360 & $<280$ \\
\hline & LRA & 37 & 39 & 270 & 240 & 123 & 86 & 190 & 360 & $<270$ \\
\hline & $\mathrm{CS}$ & 72 & 38 & 280 & 255 & I2I & 83 & 190 & 350 & $<280$ \\
\hline \multirow[t]{3}{*}{5} & HRA & 43 & 60 & 290 & 280 & 232 & 173 & 140 & 470 & 300 \\
\hline & LRA & 45 & 71 & 280 & 270 & 236 & 166 & 140 & 460 & 310 \\
\hline & CS & 79 & 39 & 320 & 300 & I76 & 138 & 150 & 450 & $<320$ \\
\hline \multirow[t]{3}{*}{6} & HRA & 83 & 96 & - & - & 301 & 202 & 130 & - & - \\
\hline & LRA & - & 68 & - & - & 200 & 135 & 140 & - & - \\
\hline & CS & 149 & 122 & - & - & 258 & 132 & 150 & - & - \\
\hline \multirow[t]{3}{*}{7} & HRA & 29 & 39 & 270 & 240 & 131 & 92 & 170 & 430 & $<270$ \\
\hline & LRA & 36 & 57 & 260 & 240 & 166 & IIO & 170 & 420 & $<260$ \\
\hline & CS & 89 & 52 & 290 & 220 & I39 & 87 & 170 & 420 & $<290$ \\
\hline \multirow[t]{3}{*}{8} & HRA & 38 & 49 & 210 & 200 & 146 & 97 & 160 & 460 & 320 \\
\hline & LRA & 52 & 73 & 320 & 300 & 140 & 67 & 170 & 430 & 340 \\
\hline & CS & 79 & 42 & 290 & 270 & 78 & 35 & 160 & 440 & 320 \\
\hline \multirow[t]{3}{*}{9} & HRA & $4 \mathrm{I}$ & 46 & 320 & I90 & 325 & 285 & 150 & 470 & 320 \\
\hline & LRA & 76 & 69 & 300 & 240 & 274 & 211 & 150 & 400 & 300 \\
\hline & CS & 145 & 58 & 305 & 300 & 216 & 155 & 150 & 460 & 320 \\
\hline \multirow[t]{3}{*}{ IO } & HRA & 70 & 70 & 350 & 340 & 242 & 172 & 130 & 530 & 445 \\
\hline & LRA & 100 & I10 & 340 & 210 & 272 & 165 & 140 & 520 & 440 \\
\hline & CS & 91 & 77 & 300 & 230 & 192 & IIO & 130 & 530 & 450 \\
\hline \multirow[t]{3}{*}{ II } & HRA & 49 & 81 & 350 & 300 & 208 & 129 & 120 & 500 & 410 \\
\hline & LRA & 52 & 52 & 280 & 240 & 152 & 102 & I40 & 420 & 310 \\
\hline & CS & 65 & 43 & 300 & 260 & 144 & 100 & 130 & 470 & 370 \\
\hline \multirow[t]{3}{*}{12} & HRA & 40 & 52 & 180 & 155 & 162 & 107 & I10 & 580 & 360 \\
\hline & LRA & 32 & 38 & 260 & 210 & 130 & 91 & I10 & 620 & 550 \\
\hline & CS & 59 & $4 I$ & 270 & 220 & 122 & 77 & 100 & 640 & 550 \\
\hline \multirow[t]{3}{*}{13} & HRA & 35 & 46 & 250 & 230 & 134 & 94 & 160 & 405 & $<250$ \\
\hline & LRA & 48 & 40 & 250 & 210 & 105 & 70 & 180 & 390 & $<250$ \\
\hline & CS & 43 & 42 & 240 & 200 & 118 & 76 & 170 & 410 & 255 \\
\hline \multirow[t]{2}{*}{14} & HRA & 34 & 45 & 295 & 275 & 167 & 120 & 170 & 400 & 295 \\
\hline & LA & 35 & 50 & 300 & 250 & 169 & 125 & 180 & 415 & 300 \\
\hline \multirow[t]{2}{*}{15} & HRA & 45 & 45 & 300 & 220 & 155 & 109 & 180 & 440 & $<300$ \\
\hline & LA & 67 & 76 & 330 & 275 & 182 & 107 & 190 & 420 & $<330$ \\
\hline \multirow[t]{2}{*}{16} & HRA & 38 & 50 & 260 & 235 & 170 & II5 & 160 & 460 & $<260$ \\
\hline & LA & 39 & 57 & 230 & 160 & 169 & III & 160 & 420 & $<230$ \\
\hline
\end{tabular}

Abbreviations: FRP-atr, funtional refractory period of the atrium; ERP-atr, effective refractory period of the atrium; $W$, paced rate producing AV nodal Wenckebach; FRP-AV, functional refractory period of the AV node; ERP-AV, effective refractory period of the AV node. 
atrial electrogram to $\mathrm{His}$ bundle electrogram, the usual measure of AV nodal conduction time; 3) S-HRA, from stimulus to high right atrial electrogram, and 4) S-A, from stimulus to low septal right atrial electrogram. The value assigned to each interval represented the mean of Io measurements in consecutive beats.

Refractory periods were measured using the atrial extra-stimulus technique at a cycle length of $667 \mathrm{~ms}$ from the three stimulation sites. In 6 patients, the refractory periods from high right atrium were also repeated at the end of the procedure, and were noted to be similar to the initial measurements. Statistical analysis was done using analysis of variance, in those patients in whom the measured variables were available for all three pacing sites. The Student t-test was used to compare left atrium against high right atrium.

\section{Results}

The detailed results obtained in the 16 patients are given in Table 2.

\section{Intra-atrial conduction (Table 3 )}

Stimulus to high right atrium conduction times were (mean $\pm S E M) 4 I \pm 3,56 \pm 6$, and $76 \pm 7 \mathrm{~ms}$ with high right atrium, low lateral right atrium, and coronary sinus pacing, respectively. Stimulus to high right atrium was significantly shorter with high right atrial pacing when compared to both coronary sinus and low lateral right atrium pacing. S-A conduction times were $6 \mathrm{I} \pm 5,64 \pm 6$, and $53 \pm 6 \mathrm{~ms}$ with high right atrium, low lateral right atrium, and coronary sinus pacing, respectively. These means were not significantly different.

Mean atrial functional refractory period was $265 \pm 19,280 \pm 9$, and $291 \pm 7 \mathrm{~ms}$ from high right atrium, low lateral right atrium, and coronary sinus, respectively (NS). Mean atrial effective refractory period was $244 \pm 16,240 \pm 8$, and $253 \pm 10 \mathrm{~ms}$ from high right atrium, low lateral right atrium, and coronary sinus pacing, respectively (NS).

\section{AV nodal conduction (Table 4)}

Mean S-H interval was $199 \pm 17,190 \pm 16$, and 162 $\pm 13 \mathrm{~ms}$ from high right atrium, low lateral right atrium, and coronary sinus, respectively (Fig. 2). Mean A-H interval was $139 \pm 16,129 \pm 13,93 \pm 8 \mathrm{~ms}$ from high right atrium, low lateral right atrium, and coronary sinus, respectively. Both $\mathrm{S}-\mathrm{H}$ and A-H were significantly shorter with coronary sinus pacing, with $P$ values of 0.05 and 0.001 , respectively. The decrease in A-H was responsible for the decrease in S-H. There was no significant difference in $\mathrm{S}-\mathrm{H}$ and $\mathrm{A}-\mathrm{H}$ when high and low lateral right atrial pacings were compared.

Mean AV nodal functional refractory period was $480 \pm 21,467 \pm 26$, and $480 \pm 26 \mathrm{~ms}$ from high right atrium, low lateral right atrium, and coronary sinus,

TABLE 3 Intra-atrial conduction

\begin{tabular}{|c|c|c|c|c|c|c|c|c|c|c|c|c|}
\hline \multirow[b]{2}{*}{ Stimulation site } & \multicolumn{3}{|c|}{$S-H R A$} & \multicolumn{3}{|l|}{$S-A$} & \multicolumn{3}{|l|}{$F R P$-atr } & \multicolumn{3}{|l|}{$E R P$-atr } \\
\hline & $H R A$ & $L R A$ & $C S$ & $H R A$ & $L R A$ & $C S$ & $H R A$ & $L R A$ & $C S$ & $H R A$ & $L R A$ & CS \\
\hline $\begin{array}{l}\text { No. of patients } \\
\text { Range (ms) } \\
\text { Mean } \pm \text { SEM }\end{array}$ & $\begin{array}{l}12 \\
29-70\end{array}$ & $\begin{array}{l}12 \\
32-100\end{array}$ & $\begin{array}{l}12 \\
43-145\end{array}$ & $\begin{array}{l}13 \\
39-96\end{array}$ & $\begin{array}{l}13 \\
37-110\end{array}$ & $\begin{array}{l}13 \\
38-122\end{array}$ & $\begin{array}{c}\text { II } \\
180-350\end{array}$ & $\begin{array}{c}\text { I I } \\
240-340\end{array}$ & $\begin{array}{c}11 \\
240-310\end{array}$ & $\begin{array}{l}\text { II } \\
\text { I55-350 }\end{array}$ & $\begin{array}{l}\text { II } \\
210-300\end{array}$ & $\begin{array}{c}\text { II } \\
200-300\end{array}$ \\
\hline$P^{(\mathrm{ms})^{-}}$ & $\begin{array}{l}4 r \pm 3 \\
<0.05\end{array}$ & $56 \pm 6$ & $\begin{array}{r}76 \pm 7 \\
<0.001\end{array}$ & $\begin{array}{l}6 \mathrm{r} \pm 5 \\
\mathrm{NS}\end{array}$ & $64 \pm 6$ & $53 \pm 6$ & $\begin{array}{l}265 \pm 19 \\
\text { NS }\end{array}$ & $280 \pm 9$ & $291 \pm 7$ & $\frac{244 \pm 16}{\mathrm{NS}}$ & $240 \pm 8$ & $253 \pm 10$ \\
\hline
\end{tabular}

Abbreviations: HRA, high right atrium; LRA, low lateral right atrium; CS, coronary sinus.

TABLE 4 AV nodal conduction

\begin{tabular}{|c|c|c|c|c|c|c|c|c|c|}
\hline & $S-H$ & & & $A-H$ & & & $F R P-A V$ & & \\
\hline Stimulation site & $H R A$ & $L R A$ & $C S$ & $H R A$ & $L R A$ & $C S$ & $H R A$ & $L R A$ & $C S$ \\
\hline $\begin{array}{l}\text { No. of patients } \\
\text { Range (ms) } \\
\text { Mean } \pm \text { SEM (ms) } \\
\text { P }\end{array}$ & $\begin{array}{l}13 \\
131-325 \\
199 \pm 17\end{array}$ & $\begin{array}{l}13 \\
105-274 \\
190 \pm 16\end{array}$ & $\begin{array}{l}13 \\
78-258 \\
162 \pm 13 \\
<0.05\end{array}$ & $\begin{array}{l}13 \\
94-285 \\
139 \pm 16\end{array}$ & $\begin{array}{l}13 \\
67-211 \\
129 \pm 13\end{array}$ & $\begin{array}{l}13 \\
35-155 \\
93 \pm 8 \\
<0.001\end{array}$ & $\begin{array}{l}\text { II } \\
360-590 \\
480 \pm 21 \\
\text { NS }\end{array}$ & $\begin{array}{c}I I \\
360-260 \\
467 \pm 26\end{array}$ & $\begin{array}{c}I I \\
350-640 \\
480 \pm 26\end{array}$ \\
\hline
\end{tabular}




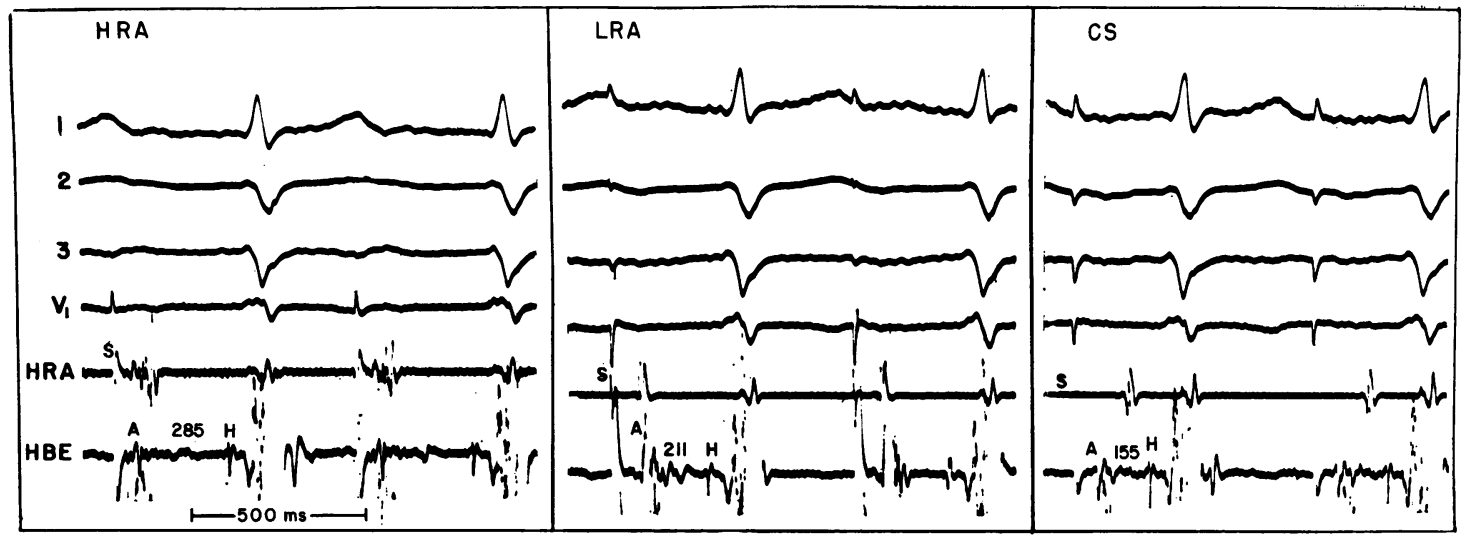

FIG. 2 Case 9. His bundle recordings obtained by pacing the atrium at three atrial sites and at identical cycle lengths of $667 \mathrm{~ms}$. Note: I) The significant shortening of $S-H$ and $A-H$ intervals by coronary sinus pacing. 2) The minimal changes in $S$ - $A$ interval between the three pacing sites, 3) The lengthening of the $S-H R A$ interval by coronary sinus pacing. $H R A=$ high right atrium; $L R A=$ low lateral right atrium; $C S=$ coronary sinus; $H B E=H i$ bundle recordings.

respectively (NS). Mean AV nodal effective refractory period was $382 \pm 20,40 \mathrm{I} \pm 36$, and $422 \pm 36 \mathrm{~ms}$ from the high right atrium, low lateral right atrium, and coronary sinus respectively (NS).

The mean pacing rates inducing AV nodal Wenckebach periods were $143 \pm 6,148 \pm 7$, and $\mathrm{r} 46 \pm 7$ beats/min from the high right atrium, low lateral right atrium, and coronary sinus, respectively (NS).

\section{Left atrial pacing}

In the three patients in whom the left atrial appendage was paced and compared against high right atrium, mean stimulus to high right atrium was $39 \pm 5 \mathrm{~ms}$ from high right atrium and $47 \pm 10 \mathrm{~ms}$ from the left atrium (NS). The mean S-A was $47 \pm 2$ $\mathrm{ms}$ from the high right atrium, and $6 \mathrm{I} \pm 8 \mathrm{~ms}$ from the left atrium (NS). Mean atrial functional refractory period was $285 \pm 13 \mathrm{~ms}$ from the high right atrium, and $287 \pm 30 \mathrm{~ms}$ from the left atrium (NS).

\begin{tabular}{|c|c|c|c|c|c|}
\hline \multirow{2}{*}{$\begin{array}{l}E R P-A V \\
H R A\end{array}$} & \multirow[b]{2}{*}{$L R A$} & \multirow[b]{2}{*}{$C S$} & \multicolumn{3}{|c|}{$\begin{array}{l}\text { Paced rate producing } A V \\
\text { nodal Wenckebach } \\
\text { (beats/min) }\end{array}$} \\
\hline & & & $H R A$ & $L R A$ & cs \\
\hline $\begin{array}{l}7 \\
300-450 \\
382 \pm 20 \\
\text { NS }\end{array}$ & $\begin{array}{l}7 \\
310-550 \\
401 \pm 36\end{array}$ & $\begin{array}{c}7 \\
255-550 \\
422 \pm 36\end{array}$ & $\begin{array}{l}13 \\
110-170 \\
143 \pm 6 \\
\text { NS }\end{array}$ & $\begin{array}{l}\text { I3 } \\
\text { I IO-I90 } \\
\text { I48 } \pm 7\end{array}$ & $\begin{array}{l}13 \\
100-190 \\
146 \pm 7\end{array}$ \\
\hline
\end{tabular}

Mean atrial effective refractory period was $243 \pm 16$ and $288 \pm 35 \mathrm{~ms}$ for high right atrium and left atrium, respectively (NS). Mean S-H was $\mathrm{I} 64 \pm 4$ $\mathrm{ms}$ from the high right atrium and $\mathrm{I} 73 \pm 4 \mathrm{~ms}$ from the left atrium (NS). Mean A-H was II \pm 3 and II $4 \pm 5 \mathrm{~ms}$ from high right atrium and left atrium, respectively (NS). Wenckebach periods occurred at $170 \pm 5$ beats/min from the high right atrium and $177 \pm 9$ beats/min from the left atrium (NS). The mean AV nodal functional refractory period was $433 \pm 18$ and $418 \pm 2 \mathrm{~ms}$ from the high right atrium and left atrium, respectively (NS). In these patients, the AV nodal effective refractory period could not be measured because of limiting atrial refractoriness.

\section{Discussion}

\section{Intra-atrial conduction}

In I9II Sir Thomas Lewis, in a classic experiment in dogs, was able to demonstrate that the conduction time from the sinoatrial node was longer to the left atrial appendage than that to the right atrial appendage, establishing a direct correlation between the distance an impulse has to travel with the time required to traverse the same tissue (Lewis, I925). Lewis suggested that atrial depolarization was radial, originating from the sinus node. In contrast, James (James, 1963; James and Sherf, 1971) has emphasized the importance of the internodal tracts, suggesting that these atrial pathways facilitate orderly atrial depolarization and uniform input to the AV node. 
In this study, two stimulation sites were selected in the right, and two in the left atrium (coronary sinus being equivalent to posterior left atrium). Stimulus to high right atrial conduction time was shortest with high right atrial pacing and longest with coronary sinus pacing, findings consistent with the location of pacing and recording sites. S-A was similar with the high right atrial, low lateral right atrial, and coronary sinus pacing, suggesting that the low right atrial septal recording site with the His bundle recording was equivalently remote from the three sites of stimulation.

The measurement of the atrial refractory periods with the extra-stimulus technique was performed with a quadripolar electrode catheter in which the distal pair of electrodes was used for pacing while the proximal pair was used for recording of local electrograms. Whether the measurements obtained represented the whole atrium or only that part of the atrium surrounding the electrode is not clear. In individual patients, there were variations in refractoriness at different atrial sites (Table 2). However, these differences were not significant when analysed for the entire group.

\section{AV nodal conduction}

Janse (1969) has suggested that the route of entry of the atrial wave front into the AV node is a partial determinant of AV nodal conduction and excitation. In the isolated rabbit heart, he was able to demonstrate that by changing the stimulation site from the crista terminalis to the interatrial septum, conduction disturbances appeared in the form of $2: 1 \mathrm{AV}$ block. Our findings by pacing from four pacing sites revealed a significant shortening of $\mathrm{S}-\mathrm{H}$ interval with coronary sinus pacing. This reflected shortening of A-H interval, since S-A was not significantly different. This finding corroborates earlier observations by Leon et al. (1970) as well as Lau et al. (1970) and Batsford et al. (1973) who observed shortening of the $P R$ when pacing the coronary sinus. Waldo et al. (1970) noted PR intervals less than $0.12 \mathrm{~s}$ when directly stimulating the low right atrium and coronary sinus.

The decrease in A-H interval with coronary sinus pacing can be explained in several ways, depending upon what basic assumptions are made. I) If it is assumed that the low right atrial septum (the A recording site) is the final common pathway for any atrial stimulus into the AV node, and that $\mathrm{A}-\mathrm{H}$ is thus a relatively direct measure of AV nodal conduction time, then the decrease in A-H with coronary sinus stimulation should reflect a true decrease in AV nodal conduction time. 2) If it is assumed that $A$ is not necessarily the final common pathway for an atrial impulse into the AV node, and thus that $\mathrm{A}-\mathrm{H}$ is not a relatively direct measure of AV nodal conduction time, then this decrease could reflect delivery of the impulse into the distal AV node (bypassing the proximal AV node), perhaps by preferential pathway (posterior internodal tract). This explanation seems unlikely, since coronary sinus stimulation did not result in any other significant facilitation of AV nodal conduction, e.g. shortening of AV nodal effective or functional refractory periods, or decrease in the paced rates producing AV nodal Wenckebach periods. 3) The decrease in A-H with coronary sinus pacing could also reflect simultaneous activation of the low atrial septum and the AV node itself, because of anatomical proximity to the pacing site. Under these circumstances, AV nodal conduction could be unchanged, despite the decrease in A-H with coronary sinus pacing. This would be compatible with the lack of change in other indices of $\mathrm{AV}$ nodal function with coronary sinus pacing.

\section{Implications regarding electrophysiological studies}

This study suggests the following conclusions: I) stimulus-atrium intervals can vary, depending upon atrial recording and stimulation sites. 2) Atrial refractory periods can vary in an individual patient, when measured from different stimulation sites. However, no specific atrial stimulation site appears to have an intrinsically shorter or longer atrial refractory period. 3) Changes in A-H interval can be expected when pacing from different atrial sites in a given patient. A-H is shorter with coronary sinus stimulation. 4) AV nodal refractory periods may vary in an individual patient, when studied from different atrial stimulation sites. In the group as a whole, no specific atrial site is associated with significantly longer or shorter AV nodal refractory periods.

The results imply that when performing electrophysiological studies in which the patient serves as his own control (for example, during a drug study), then the stimulation site should be kept constant. When comparing different groups of patients, it is probably also advisable to use similar pacing sites. The high right atrial pacing site seems to be the most physiological site, since this most closely approximates to the normal sequence of atrial activation.

\section{References}

Batsford, W. P., Akhtar, M., Caracta, A. R., Josephson, M. E., Seides, S. F., and Damato, A. N. (1973). Effect of atrial stimulation site on the electrophysiological properties of the atrioventricular conduction system (abstract). Circulation, 48, Suppl. IV, ror.

Denes, P., Wu, D., Dhingra, R., Pietras, R. J., and Rosen, K. M. (1974). The effects of cycle length on cardiac refractory periods in man. Circulation, 49, 32. 
James, T. N. (1963). The connecting pathways between the sinus node and A-V node and between the right and left atrium in the human heart. American Heart fournal, 66, 498.

James, T. N., and Sherf, L. (1971). Specialized tissues and preferential conduction in the atria of the heart. American Fournal of Cardiology, 28, 414.

Janse, M. J. (1969). Influence of the direction of the atrial wave front on A-V nodal transmission in isolated hearts of rabbits. Circulation Research, 25, 439.

Lancaster, J. F., Leonard, J. J., Leon, D. F., Kroetz, F. W., and Shaver, J. A. (1965). The experimental production of coronary sinus rhythm in man. American Heart fournal, 70, 89.

Lau, S. H., Cohen, S. I., Stein, E., Haft, J. I., Rosen, K. M., and Damato, A. N. (1970). $P$ waves and $P$ loops in coronary sinus and left atrial rhythms. American Heart Fournal, 79, 201.
Leon, D. F., Lancaster, J. F., Shaver, J. A., Kroetz, F. W., and Leonard, J. J. (1970). Right atrial ectopic rhythms. Experimental production in man. American fournal of Cardiology, 25, 6.

Lewis, T. (1925). The Mechanism and Graphic Registration of the Heart Beat, 3rd ed. Shaw and Sons, London.

Scherlag, B. J., Lau, S. H., Helfant, R. H., Berkowitz, W. D., Stein, E., and Damato, A. N. (1969). Catheter technique for recording His bundle activity in man. Circulation, 39, I3.

Waldo, A. L., Vitikainen, K. J., Kaiser, G. A., Malm, J. R., and Hoffman, B. F. (1970). The $P$ wave and $P-R$ interval. Effects of the site of origin of atrial depolarization. Circulation, 42, 653 .

Requests for reprints to Dr. Kenneth M. Rosen, Cardiology Section, University of Illinois Hospital, P.O. Box 6998, Chicago, Illinois 60680, U.S.A. 